\title{
Impact of oestrogen deficiency and aging on tendon: concise review
}

\author{
Antonio Frizziero \\ Filippo Vittadini \\ Giuseppe Gasparre \\ Stefano Masiero
}

Department of Physical and Rehabilitation Medicine, University of Padova, Italy

\author{
Corresponding author: \\ Antonio Frizziero \\ Department of Physical and Rehabilitation Medicine, \\ University of Padova \\ Via Giustiniani 2 \\ 35128 Padova, Italy \\ E-mail: antonio.frizziero@unipd.it
}

\section{Summary}

The knowledge about tendons and tenocyte biological behaviour during aging and, especially, oestrogen deficiency is limited. Women differ from men with regard to muscle and tendon, most likely due to differences in sex hormones activity and tissue response. To-date the interest in metabolic factors that may induce tendon disorders is growing. The aim of this paper is to elucidate the current findings in the correlation between oestrogen deficiency, aging and tendon pathology and to encourage future researches to ameliorate assessment and management of tendinopathies in postmenopausal women.

KEY WORDS: tendinopathies, metabolic disease, oestrogens hormones.

\section{Introduction}

During aging occur paraphysiological changes in the musculoskeletal system such as decrease in musclemass and strength, alteration of tendon and bone structure $^{1}$. It was observed that these alterations are due to a decrease in collagen synthesis, increase in free radicals expression and metabolism imbalance in favor of catabolic activity ${ }^{2,3}$. It was suggested that in females the level of estrogen, which decreases drastically in the post-menopause period, plays a crucial role influencing tendon metabolism and altering the production of different growth factors ${ }^{4}$. Menopause consist in a rapid oestrogen decrease in the first 6 months, that continues for about 3 years. At the same times is observed the peak concentration of gonadotrophins ${ }^{5}$. For the rest of woman life the level of estradiol and estrone remains constantly very low, without the typical periodic fluctuation that characterize fertile period ${ }^{6}$. Before menopause the risk of developing tendon pathology in women is lower than in men $^{7}$, whereas in older women the incidence of tendinopathy and tendon rupture is similar to coetaneous men ${ }^{8,9}$. It is also been shown that dynamic adaptation to mechanic loading may be different between women and men ${ }^{10}$.

In a recent study conducted by Abate et al. it was observed that in postmenopausal women there is a dramatic increase in asymptomatic rotator cuff tears and that this higher prevalence was linked also to other metabolic factors like HDL, fasting glucose and Body Mass Index (BMI) ${ }^{11}$.

\section{Materials and methods}

We performed a comprehensive search of PubMed, Medline, Cochrane, CINAHL, Embase, Sport Discus, Pedro and Google scholar databases using various combinations of the keywords 'postmenopausal women', 'tendinopathy', 'tendon', 'oestrogen deficiency', 'aging'. Selected literature was limited to original articles and to English, Italian and Spanish Ianguages. This article submits to the ethical standards of the journal12.

Aging and tendon: preclinical and clinical findings

Tendons primarily consist of collagen, arranged in linear fibrils, in which tenocytes are the main cellular component ${ }^{13}$. Tenocytes produce collagen, repair proteins, and matrix proteoglycans. Thus, the function, mechanics and homeostasis of tendon tissue depend on the activity of tenocyte, which is essential to maintain tendon characteristics by the capacity of remodel extracellular matrix $(\mathrm{ECM})^{14}$.

Age-related changes in tenocyte behavior are responsible for altered migration and proliferation rate, leading to ineffective repair processes and increase in frequency of tendon injuries ${ }^{15}$.

Tsai et al. in an in vitro experiment performed on tenocytes derived from young, middle-age and old SpragueDawley rats, showed that decline in proliferation is di- 
rectly correlated to aging and that aged tenocytes tend to stop in G0/G1 cellular phase. Furthermore, in tenocytes from old rats, it was observed down-regulation in cellular senescence-inhibited gene (CSIG), up-regulation in p27 (a CDK inhibitor that arrest cell cycle) and over-expression of senescence-associated b-galactosidase (SA b-gal) has been proposed to be a universal marker of aging ${ }^{3,16}$.Torricelli et al. confirmed the reduction in tenocyte proliferation rate, in an in vitro study on tenocytes derived from Achilles tendon of rats. Furthermore, it was observed age-related lower production of collagen I, aggrecan and elastin ${ }^{4}$. The decrease in collagen I production is in accordance with other studies performed in vitro and in vivo ${ }^{17-19}$.

Recently stem cells, which are called tendon-derived mesenchymal stem cells (TD-MSCs), have been identified both in human and animal tendons ${ }^{20}$. Beside stenocytes, stem cell population may be involved in tendon homeostasis and repair, by replacing mature cells lost, or in the pathogenesis of tendinopathy ${ }^{21}$. Ruzzini et al. found that the number of tendon stem cells and self renewal potential are reduced in old patients compared to young patients, leading a possible role of impaired stem cell potential and variation in tendon structure during aging 22 .

Although different studies in various animal models report alterations in tendon stiffness, fibril structure and collagen content during aging, the findings of modifications in tendon mechanical properties are contradictory ${ }^{23}$. Wood et al. found age-related increase in tangent modulus in old rats tibialis anterior tendon, but no differences in cross sectional area (CSA) or in fibril diameter and morphology 24 . Similar results were obtained in tibialis anterior and flexor digitorumlongus muscle tendons with a significant increase of the elastic stiffness with aging in rats ${ }^{25,26}$. On the other hand there are also evidence to the opposite, with decrease or constant stiffness related to age ${ }^{27,28}$. Equally, also human trials performed are inconsistent, which may partly be related to methodological study design and physical activity level differences of the sample. Indeed, some author shave shown alteration in mechanical properties ${ }^{29-32}$ while others have not shown any significant variation between young and old patients ${ }^{31,32,34,35}$. Furthermore, tendon stiffness during aging may be influenced by the accumulation of Advanced Glycation End-Products (AGEs) ${ }^{36}$. AGE formation is high in tendon tissue because the turnover of mature collagen is slow, leaving enough space for further cross-linking through non-enzymatic reactions ${ }^{37}$. Couppè et al. found that both enzymatic cross-links and pentosidine, which is a marker of AGE, where more abundant in the patellar tendon of old men compared with that of young men and they supposed that higher non-enzymatic cross-link density in elderly served to maintain tendon stiffness despite the diminished collagen concentration ${ }^{33}$. Li et al. observed that AGE accumulation may significantly reduce collagen fiber sliding without tendon structure stiffening even if it was reveal a compensatory collagen fiber stretch ${ }^{38}$.
Recently, the contribution of non-collagenous proteins of extra-cellular matrix has been closely studied, considering that age related alterations in proteoglycans (PGs) may affect the structure and mechanical properties of tendon ${ }^{39}$. To-date class I small leucine-rich proteoglycans (SLRPs), biglycan and decorin have been identified as important regulators of tendon development, aging and healing ${ }^{40}$.

\section{Oestrogen deficiency and tendon: preclinical and clinical findings}

The presence of oestrogen receptors (ER) in tenocytes is been demonstrated in human and animal trials ${ }^{41,42}$. These findings may indicate that tenocytes are influenced by oestrogen level. Bridgeman et al. observed both $E R \alpha$ and $E R \beta$ in normal and disease tendon of male and female patients, without any statistically significant difference. On the other hand the impact of ovariohysterectomy (OVH) on gene expression in rabbit resulted different in various tendons that may indicate variances in number and distribution of oestrogen receptors ${ }^{43,44}$.

Oestrogen level has a direct effect on collagenous tissue in severalpreclinical studies. The reduction of blood oestrogen level is associated with reduction in tensile strength ${ }^{45}$, decrease in collagen synthesis, fibre diameter, density and increase degradation in tendon tissue ${ }^{46}$.

Circi et al. found a correlation between oestrogen deficiency, down-regulation of collagen turnover and alteration in collagen fibre orientation. Furthermore the group composed by sham-operated rats exhibits a greater tenocyte proliferation rate and inflammatory response after an Achilles tendon injury compared with oophorectomised oestrogen-deficient rats, meaning a potential role of endogenous oestrogens in improving tendon healing ${ }^{47}$. This could be explained by a direct effect of oestrogen deficiency on tenocytes. Indeed, in a micro-wound in vitro model, tenocytes derived from ovariectomised rats show less tenocyte viability, cell migration speed and a poor quality of healed tissue in comparison not only to tenocytes derived from healthy young rats but also to tenocytes derived from old rats ${ }^{4}$. The reduction in tensile strength and alteration in biomechanical properties are linked not only to the role of collagen but also to changes in gene expression of other important extracellular matrix (ECM) molecules like proteoglycans, inflammatory mediators and growth factors. Recently it was observed a 10-fold lower expression of aggrecan and decrease in other PGs (biglycan, decorin, versican) in $\mathrm{OVH}$ rabbits, moreover it was also measured decrease in tissue inhibitor of metalloproteinase (TIMP-2) and TGF-beta production that is correlated to imbalanced tendon metabolism ${ }^{14,48}$.

In rabbits tendons the impact of $\mathrm{OVH}$ was different for Achilles tendon comparing to patellar tendon when evaluated using mRNA levels for genes including collagenes, proteoglycans, proteinases and inflammatory mediators. This results may indicate that different ten- 
dons have different response to oestrogens and a tendon-specific action of sex hormones ${ }^{49}$.

Most of studies performed on tendon and oestrogen deficiency are clinical and are founded on the administration of oestrogen replacement therapy in postmenopausal women ${ }^{50,51}$. However currently are been performed trials exclusively in Achilles and patellar tendons. Hormone Replacement Therapy (HRT) with exogenous oestrogen may ameliorate tendon structure by preserving collagen fibre diameter. Furthermore oestrogen positively influences tendon morphology and biomechanical properties in postmenopause ${ }^{52}$. In contrast with these findings, the effects of steroids hormones on tendons seems to be different in young women. Indeed, while in younger women estrogens stimulation seems to have negative effects on tendons, in older post-menopausal women they seems to have stimulating effects. In fact, in a study performed in young women, oral contraceptive users group was found to have lower collagen synthesis rate, compared to coetaneus control women ${ }^{53}$.

Conflicting results were obtained combining HRT and exercise therapy. In rats exercise therapy increases mature collagen replacement and fibril diameter and density, while detraining is associated with disorganization in collagen fibre arrangement ${ }^{54}$.

Cook et al. and Finni et al. reveal positive effect on Achilles tendon morphology in active postmenopausal women receiving $\mathrm{HRT}^{55,56}$. On the other hand Hansen et al. found a negative correlation between tendon strength and HRT use following one-legged resistance exercise related to increasing in collagen turnover with higher immature collagen cross-linking ${ }^{57}$. The discrepancy could be partially explained by the observation that oral oestrogen replacement influences liver metabolism $^{58}$. Specifically, oral administration may reduce circulating level of Insuline-like Growth Factor I (IGF-I) and Interleukin-6 (IL-6), that are involved in collagen synthesis during physical activity ${ }^{59}$. Nevertheless, these contradictory findings may be consequent to the type of therapeutic exercise ordered to patients. Indeed, in athlete tendinopathy, eccentric exercise programs are widely used in the rehabilitation of mid-portion Achilles and patellar tendon injuries with a successful outcome 60 . In older adults it has been revealed general preservation of eccentric strength compared to concentric strength ${ }^{61}$ and increase muscle mass and strength in high-intensity resistance training incorporating eccentric contractions relative to traditional training strategies $^{62}$. Therefore, eccentric exercise may be promising also in the prevention of tendon disorders in postmenopausal women.

\section{Future perspectives}

The relationship between oestrogen deficiency and tendon disorders during aging appears clinical relevant. Thus more studies are needed to investigate the impact of menopause in different tendons, especially in upper limb and in rotator cuff tendinopathy that dramatically increase in middle-aged women. Improvements in the understanding about this argument may rebuild assessment and management in tendon pathology.

\section{References}

1. Keller $\mathrm{K}$, Engelhardt M. Strenght and muscle mass loss with aging process. Age and strength loss. MLTJ. 2013;3(4):346350.

2. Yu T-Y, Pang J-H, Wu KP, Chen M. Aging is associated with increased activities of matrix metalloproteinase- 2 and -9 in tenocytes. BMC Muscoloskeletal disorders. 2013;14:2.

3. Tsai WC, Chang HN, Yu T-Y, Chien CH, Fu LF. Decreased proliferation of aging tenocytes is associated with down-regulation of cellular senescence-inhibited gene and up-regulation of p27. J Orthop Res. 2011;29(10):1598-1603.

4. Torricelli $\mathrm{P}$, Veronesi $\mathrm{F}$, Pagani $\mathrm{S}$, et al. In vitro tenocyte metabolism in aging and oestrogen deficiency. AGE. 2013;35: 2125-2136.

5. Sipila S, Narici M, Kjaer M, et al. Sex hormones and skeletal muscle weakness. Biogerontology. 2013;14:231-245.

6. Rannevik G, Jeppsson S, Johnell O, Bjerre B, Laurell-Borulf Y, Svanberg L. A longitudinal study of the perimenopausal transition: altered profiles of steroid and pituitary hormones, SHBG and bone mineral density. Maturitas. 2008;61:67-77.

7. Cook JL, Khan KM, Harcourt PR, et al. Patellar tendon ultrasonography in asymptomatic active athletes reveals hypoechoic regions: a study of 320 tendons. Victorian Institute of Sport Tendon Study Group. Clin J Sport Med. 1998;8(2):7377.

8. Maffulli N, Waterston SW, Squair J, Reaper J, Douglas AS. Changing incidence of Achilles tendon rupture in Scotland: a 15-year study. Clin J Sport Med. 1999;9(3):157-160.

9. Tauton J, Ryan M, Clement D. A retrospective case-control analysis of 2002 running injuries. Br J Sport Med. 2002;36:95101.

10. Magnusson SP, Hansen $\mathrm{M}$, Langberg $\mathrm{H}$, et al. The adaptability of tendon to loading differs in men and women. Int J Exp Pathol. 2007;88(4):237-240.

11. Abate M, Schiavone C, Di Carlo L, Salini V. Prevalence of and risk factors for asymptomatic rotator cuff tears in postmenopausal women. Menopause. 2014;21(3):275-280.

12. Padulo J, Oliva F, Frizziero A, Maffulli N. Muscles, Ligaments and Tendons Journal. Basic principles and recommendations in clinical and field science research. MLTJ. 2013;4:250-252.

13. Kirkendall DT, Garrett WE. Function and biomechanics of tendons. Scand J Med Sci Sports. 1997;7:62-66.

14. Dudhia J, Scott CM, Draper ERC, Heinegard D, Pitsillides AA, Smith RK. Aging enhances a mechanically-induced reduction in tendon strenght by an active process involving matrix metalloproteinase activity. Aging Cell. 2007;6:547-556.

15. McCharty MM, Hannafin JA. The Mature Athlete: Aging Tendon and Ligament. Sports Health. 2014;6(1):41-48.

16. Dimri GP, Lee X, Basile G, et al. A biomarker that identifies senescent human cells in culture and in aging skin in vivo. Proc Natl Acad Sci. USA. 1995;92:9363-9367.

17. Arnesen SM, Lawson AM. Age-related changes in focal adhesion lead to altered cell behavior in tendon fibroblasts. Mech Ageing Dev. 2006;127:726-732.

18. Kostrominova TY, Brooks SV. Age-related changes in structure and extracellular matrix protein expression levels in rat tendons. AGE. 2013;35:2203-2214.

19. Thorpe CT, Streeter I, Pinchbeck GL, Goodship AE, Clegg PD, Birch HL. Aspartic acid racemization and collagen degradation markers reveal an accumulation of damage in tendon collagen that is enhanced with aging. J Biol Chem. 2010;285(21):1567415681. 
20. Via AG, Frizziero A, Oliva F. Biological properties of mesenchymal Stem Cells from different sources. MLTJ. 2012;2(3):154-162.

21. Zhou Z, Akinbiyi T, Xu L, et al.Tendon-derived stem/progenitor cell aging: defective self renewal and altered fate. Aging Cell. 2010; 9:911-915.

22. Ruzzini L, Abbruzzese F, Rainer A, et al. Characterization of age-related changes of tendon stem cells from adult human tendons. Knee Surg Sports Traumatol Arthrosc. 2013.

23. Connizzo BK, Sarver JJ, Birk DE, Soslowsky LJ, lozzoRV. Effect of age and proteoglycan deficiency on collagen fiber realignment and mechanical properties in mouse supraspinatus tendon. J Biomech Eng. 2013;135(2):021019.

24. Wood LK, Arruda EM, Brooks SV. Regional stiffening with aging in tibialis anterior tendons of mice occurs independent of changes in collagen fibril morphology. J Appl Physiol (1985). 2011;111(4):999-1006.

25. Nielsen HM, Skalicky M, Viidik A. Influence of physical exercise on aging rats. III. Life-long exercise modifies the aging changes of the mechanical properties of limb muscle tendons. Mech Ageing Dev. 1998;100(3):243-260.

26. Viidik A, Nielsen HM, Skalicky M. Influence of physical exercise on aging rats. II. Life-long exercise delays aging of tail tendon collagen. Mech Ageing Dev. 1996;88:139-148.

27. Vogel HG. Influence of maturation and age on mechanical and biochemical parameters of connective tissue of various organs in the rat. Connect Tissue Res. 1978;6(3):161-166.

28. Goh KL, Holmes DF, Lu HY, et al. Ageing changes in the tensile properties of tendons: influence of collagen fibril volume fraction. J Biomech Eng. 2008;130(2):021011.

29. Kubo K, Ishida Y, Komuro T, Tsunoda N, Kanehisa H, Fukunaga $\mathrm{T}$. Age-related differences in the force generation capabilities and tendon extensibilities of knee extensors and plantar flexors in men. J Gerontol A BiolSci Med Sci. 2007;62:12521258.

30. Kubo K, Morimoto M, Komuro T, Tsunoda N, Kanehisa H, Fukunaga T. Age-related differences in the properties of the plantar flexor muscles and tendons. Med Sci Sports Exerc. 2007;39:541-547.

31. Karamanidis K, Arampatzis A. Mechanical and morphological properties of human quadriceps femoris and triceps surae muscle-tendon unit in relation to aging and running. $J$ Biomech. 2006;39:406-417.

32. Mian OS, Thom JM, Ardigo LP, Minetti AE, Narici MV. Gastrocnemius muscle-tendon behaviour during walking in young and older adults. Acta Physiol (Oxf). 2007;189:57-65.

33. Couppé $\mathrm{C}$, Hansen $\mathrm{P}$, Kongsgaard $\mathrm{M}$, et al. Mechanical properties and collagen cross-linking of the patellar tendon in old and young men. J Appl Physiol (1985). 2009;107(3):880-886.

34. Carroll CC, Dickinson JM, Haus JM, et al. Influence of aging on the in vivo properties of human patellar tendon. J Appl Physiol (1985). 2008;105(6):1907-1915.

35. Dressler MR, Butler DL, Boivin GP. Age-related changes in the biomechanics of healing patellar tendon. J Biomech. 2006;39(12):2205-2212.

36. Reddy GK. Cross-linking in collagen by non-enzymatic glycation increases the matrix stiffness in rabbit Achilles tendon. Exp Diabesity Res. 2004;5:143-153.

37. Thorpe CT, Streeter I, Pinchbeck GL, Goodship AE, Clegg PD, Birch HL. Aspartic acid racemization and collagen degradation markers reveal an accumulation of damage in tendon collagen that is enhanced with aging. J Biol Chem. 2010;285:1567415681.

38. Li Y1, Fessel G, Georgiadis M, Snedeker JG. Advanced glycationend-products diminish tendon collagen fiber sliding. Matrix Biol. 2013;32(3-4):169-177.

39. Dourte LM, Pathmanathan L, Jawad AF, et al. Influence of decorin on the mechanical, compositional, and structural prop- erties of the mouse patellar tendon. J Biomech Eng. 2012; 134(3):031005

40. Dunkman AA, Buckley MR, Mienaltowski MJ, et al. The injury response of aged tendons in the absence of biglycan and decorin. Matrix Biol. 2014;35:232-238.

41. Hart DA, Archambault JM, Kydd A, Reno C, Frank CB, Herzog W. Gender and neurogenic variables in tendon biology and repetitive motion disorders. Clin Orthp Rel Res. 1998; 351:4456.

42. Bridgeman JT, Zhang Y, Donahue H, Wade AM, Juliano PJ Estrogen receptor expression in posterior tibial tendon dysfunction: a pilot study. Foot Ankle Int. 2010;31:1081-1084.

43. Huisman ES, Andersson G, Scott A, Reno CR, Hart DA, Thornton GM. Regional molecular and cellular differences in the female rabbit Achilles tendon complex: potential implications for understanding responses to loading. J Anat. 2014 224:538-547.

44. Hansen M, Kjaer M. Influence of Sex and Estrogen on Musculo-Tendinous Protein Turnover at Rest and After Exercise. Exerc Sport Sci Rev. 2014.

45. Slauterbeck J, Clevenger C, Lundberg W, Burchfield DM. Estrogen level alters the failure load of the rabbit anterior cruciate ligament. J Orthop Res. 1999;17:405-408.

46. Burgess KE, Pearson SJ, Onambèlè GL. Patellar tendon properties with fluctuating menstrual cycle hormones. J Strength Cond Res. 2010;24(8):2088-2095.

47. Circi E, Akpinar S, Balcik C, et al. Biomechanical and histological comparison of the influence of oestrogen deficient state on tendon healing potential in rats. Int Orthop. 2009; 33:14611466.

48. Del Buono A, Oliva F, Osti L, Maffulli N. Metalloproteases and tendinopathy. MLTJ. 2013; 3(1):51-57.

49. Hart D, Franck X, Kydd A, Ivie T, Sciore P, Reno C. Neurogenic, Mast Cell, and Gender Variables in Tendon Biology: Potential Role in Chronic Tendinopathy. In: TendonInjuries: Basics science and Clinical Medicine (Maffulli N, Renstrom P, Leadbetter WB). Ed. Springer, 2005;40-48.

50. Bryant AL, Clark RA, Bartold S, et al. Effects of oestrogen on the mechanical behaviour of the human Achilles tendon in vivo. J appl Physiol. 2008;105(4):1035-1043.

51. Pingel $\mathrm{J}$, Langberg $\mathrm{H}$, Skovgård $\mathrm{D}$, et al. Effects of transderma estrogen on collagen turnover at rest and in response to exercise in postmenopausal women. J Appl Physiol (1985). 2012 Oct;113(7):1040-1047.

52. Hansen M, Kjaer M. Influence of sex and estrogenon musculotendinous protein turnover at rest and after exercise. Exerc Sport Sci Rev. 2014 Oct;42(4):183-192.

53. Hansen M, Miller BF, Holm L, et al. Effect of administration of oral contraceptives in vivo on collagen synthesis in tendon and muscle connective tissue in young women. J Appl Physiol. 2009;106:1435-1443.

54. Frizziero A, Fini M, Salamanna F, Veicsteinas A, Maffulli N Marini M. Effect of training and sudden detraining on the patellar tendon and its enthesis in rats. BMC Musculoskelet Disord. 2011;12:20.

55. Cook JL, Bass SL, Black JE. Hormone therapy is associated with smaller Achilles tendon diameter in active post-menopausal women. Scand J Med Sci Sports. 2007;17:128-132.

56. Finni T, Kovanen V, Ronkainen PHA, et al. Combination of hormone replacement therapy and high physical activity is associated with differences in Achilles tendon size in monozygotic female twin pairs. J App Physiol. 2009;106: 1332-1337.

57. Hansen M, Kongsgaard M, Holm L, et al. Effect of estrogen on tendon collagen synthesis, tendon structural characteristics, and biomechanical properties in postmenopausal women. Appl Physiol (1985). 2009;106(4):1385-1393.

58. Bellantoni MF, Vittone J, Campfield AT, Bass KM, Harman SM, 
Blackman MR. Effects of oral versus transdermal estrogen on the growth hormone/insulin-like growth factor I axis in younger and older postmenopausal women: a clinical research center study. J Clin Endocrinol Metab. 1996;81:2848-2853.

59. Hansen M, Boesen A, Holm L, Flyvbjerg A, Langberg H, Kjaer M. Local administration of insulin-like growth factor-I (IGF-I) stimulates tendon collagen synthesis in humans. Scand J Med Sci Sports. 2013;23(5):614-619.

60. Frizziero A, Trainito S, Oliva F, Nicoli Aldini N, Masiero S, Maf- fulli N. The role of eccentric exercise in sport injuries. Rehabilitation. Br Med Bull. 2014;110(1):47-75.

61. Roig M, Macintyre DL, Eng JJ, Narici MV, Maganaris CN, Reid WD. Preservation of eccentric strength in older adults: Evidence, mechanisms and implications for training and rehabilitation. Exp Gerontol. 2010;45(6):400-409.

62. Reeves ND, Maganaris CN, Narici MV. Plasticity of dynamic muscle performance with strength training in elderly humans. Muscle Nerve. 2005;31(3):355-364. 